\title{
Combined Effects of Temperature and Nutrient Availability on Growth and Phlorotannin Concentration of the Brown Alga Sargassum patens (Fucales; Phaeophyceae)
}

\author{
Hikaru Endo, Kentaro Suehiro, Junji Kinoshita, Xu Gao, Yukio Agatsuma
}

Graduate School of Agricultural Science, Tohoku University, Sendai, Japan.

Email: h-endo@bios.tohoku.ac.jp

Received October $15^{\text {th }}, 2013$; revised November $16^{\text {th }}, 2013$; accepted November $29^{\text {th }}, 2013$

Copyright (C) 2013 Hikaru Endo et al. This is an open access article distributed under the Creative Commons Attribution License, which permits unrestricted use, distribution, and reproduction in any medium, provided the original work is properly cited.

\begin{abstract}
Global warming is predicted to affect plant-herbivore interactions. However, little is known about the effects of temperature on marine plant secondary chemistry and how these effects may impact plant-herbivore interactions. As marine macroalgae can become physiologically stressed due to warm water temperatures and nutrient-poor conditions during summer, we conducted a culture experiment to test the combined effects of temperature $\left(10^{\circ} \mathrm{C}, 20^{\circ} \mathrm{C}, 30^{\circ} \mathrm{C}\right)$ and nutrient availability (seawater enriched with $25 \%$ PESI medium and non-enriched seawater) on relative growth rate (RGR) and concentration of phlorotannins (i.e., defensive compounds) in the upper and lower parts of shoots of the brown alga Sargassum patens. RGR was affected by temperature but not by nutrient availability. Phlorotannnin concentration was affected by nutrient availability but not by temperature, although there was a significant interaction between temperature and part of the shoots. Correlations between RGR and phlorotannin concentration were significant for the upper part of the shoots but not for the lower part. These correlations were slightly positive in the nutrient-enriched medium but negative in the non-enriched medium. These results suggest that temperature affects phlorotannin concentration of $S$. patens indirectly via changes in the growth rate and that its effect depends on the part of the shoot and nutrient availability.
\end{abstract}

Keywords: Climate Change; Plant-Animal Interaction; Anti-Herbivore Defense; Secondary Metabolite; Habitat-Forming Macroalgae

\section{Introduction}

Global warming is predicted to change plant-herbivore interactions in terrestrial environments. Result of metaanalysis showed that elevated temperature had a favorable effect on the performance of insect herbivores and an inconsistent effect on the secondary chemistry of plants [1]. Responses of defensive secondary compounds appear to depend on the plant species and the chemical type. For example, concentrations of nonstructural carbohydrates and phenolics decreased under elevated temperature, whereas terpene concentration increased at high temperature $[1,2]$.

Warming is also predicted to affect marine plant-herbivore interactions. For example, O'Connor [3] reported that an increase in temperature from $23^{\circ} \mathrm{C}$ to $29^{\circ} \mathrm{C}$ did not affect the palatability of the brown alga Sargassum filipendula but did increase its rate of consumption by the amphipod Ampithoe longimana. In contrast, Poore et al. [4] found that a temperature increase from $23^{\circ} \mathrm{C}$ to $26^{\circ} \mathrm{C}$ increased the palatability of the brown algae Sargassum linearifolium but had no effect on the feeding rates of the amphipod Peraphithoe parmerong. Sudatti et al. [5] reported that the concentration of defensive compounds (elatol) in the red alga Laurencia dendroidea increased with increasing temperature between $15^{\circ} \mathrm{C}$ and $25^{\circ} \mathrm{C}$ but decreased at $30^{\circ} \mathrm{C}$ (also see reference therein). However, little information is available about the effects of temperature on marine macroalgal secondary chemistry and how these effects may impact plant-herbivore interactions.

Large brown algae that belong to the orders Laminariales (kelp) and Fucales (fucoid), including Sargassum spp., are the dominant taxa on intertidal and subtidal rocky shores in temperate and subarctic regions of the world $[6,7]$ and play an ecologically important role by provid- 
ing habitats and nurseries to a wide range of organisms $[8,9]$. These algae can become physiologically stressed due to the combined effects of above-average temperatures and nutrient-poor conditions during summer $[7,10]$, and they frequently experience intensive grazing by herbivorous animals such as molluses, sea urchins, and fishes [11]. Brown algae contain unique compounds called phlorotannins, which are known to have secondary roles as chemical defenses (e.g., herbivore deterrents, digestion inhibitors, antibacterial agents, and UV screens) and primary roles in constructing and strengthening the cell walls [12]. The concentrations of phlorotannins are known to be affected by abiotic and biotic factors such as nutrient availability, UV-B radiation, and grazing [12], but little is known about the effect of temperature. Poore et al. [4] reported that elevated temperature (from $23^{\circ} \mathrm{C}$ to $26^{\circ} \mathrm{C}$ ) had no effect on the phlorotannin concentration of S. linearifolium. However, temperature might affect phlorotannin concentration indirectly via changing the growth rate of brown algae, as phlorotannin concentrations reportedly decrease with increasing growth rate [13-16]. Hence, to estimate the direct or indirect effect of temperature on phlorotannin concentration, the effects of minimal and optimal growth temperature on phlorotannin concentration need to be tested. Moreover, the temperature effect might be influenced by nutrient availability, as nutrient limitation might increase resource allocation to defensive secondary metabolites [13]. In addition, response of phlorotannin concentration to abiotic factor might differ between upper and lower parts of shoots in Sarggassum spp., as reported by Hay et al. [17].

In southern Japan, decline of dominant kelp Ecklonia spp. and distributional shifts of dominant fucoid Sargassum spp. were observed in response to recent warming during the last few decades [18]. These algae are also currently experiencing intensive herbivory by the endemic fish species, because warming allows these fish species to graze actively for longer periods from summer to winter [19]. However, there was no study to test the possibility that elevated temperature might increase the palatability of Japanese Sargassum spp.

Sargassum patens is one of the dominant species on subtidal rocky shores around Japan [20], including Hong Kong [21]. This species has a perennial discoid holdfast, some perennial short stipes, and many annual shoots that are produced during summer, grow from autumn to spring, and decay the next summer after maturation $[21,22]$. Physiological studies of Sargassum spp. have been conducted via culture experiment using shoots excised from the holdfast or stipe [23-25], but this procedure can be problematic because differences in the ratio of axes, leaves, and vesicles within a shoot affect physiological parameters such as photosynthetic rate [26]. S. patens has flat axes that are indistinguishable from their flat leaves [20] (see Figure 1), thus physiological differences between axes and leaves might be relatively small. Hence, the new short shoots excised from this species during summer are suitable for culture experiments in flasks to test the effect of various abiotic factors, including warm summer temperature. Moreover, optimal and critical temperatures for survive of this species already have been estimated to be $20^{\circ} \mathrm{C}-25^{\circ} \mathrm{C}$ and $31^{\circ} \mathrm{C}$, respectively, based on culture experiments using excised shoots [27].

In the present study, we conducted a culture experiment using excised shoots of $S$. patens to test the combined effect of temperature and nutrient availability on growth and phlorotannnin concentration. Because S. patens experiences temperatures ranging from ca. $10^{\circ} \mathrm{C}$ (winter temperature at its northern limit) to $30^{\circ} \mathrm{C}$ (summer temperature at its southern limit) within its distributional range and its optimal growth temperature is $20^{\circ} \mathrm{C}$ $25^{\circ} \mathrm{C}$ [27], excised shoots from this species were cultured at $10^{\circ} \mathrm{C}, 20^{\circ} \mathrm{C}, 30^{\circ} \mathrm{C}$ in both nutrient-enriched medium and non-enriched seawater. Relative growth rate (RGR) and phlorotannin concentration of S. patens were measured in each treatment. We addressed the following questions: 1) Is the effect of temperature on phlorotannin concentration significant? 2) Does temperature have an indirect effect on phlorotannin concentration by changing the growth rate? 3) Does the effect of temperature differ between the upper and lower parts of the shoots? 4) Does nutrient availability influence the effect of temperature on phlorotannin concentration?

\section{Materials and Methods}

\subsection{Culture Experiment}

S. patens specimens with several short shoots were collected in July 2012 from a sheltered site along the coast at Unosaki (39 $\left.59^{\prime} 20^{\prime \prime} \mathrm{N}, 139^{\circ} 48^{\prime} 56^{\prime \prime} \mathrm{E}\right)$, which is located on the Oga Peninsula, Akita Prefecture, northern Japan. These specimens were transported to our laboratory in insulated cool boxes, and apical shoots without vesicles

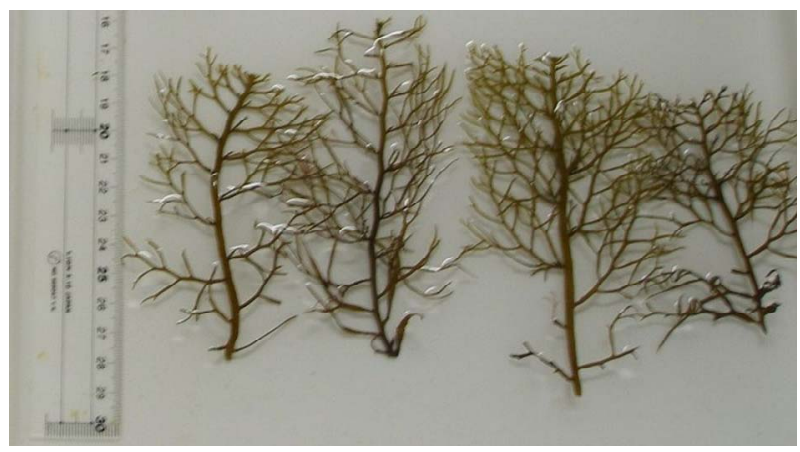

Figure 1. Shoot morphology of the brown alga S. patens. 
were excised from each specimen (Figure 1). To reduce the negative effects of excision, these shoots were placed in flasks containing $500 \mathrm{ml}$ of enriched $25 \%$ PESI medium [28], which was made using filtered seawater pumped from Unosaki. These shoots were maintained in incubators with aeration at the optimal growth temperature $\left(20^{\circ} \mathrm{C}\right)$ for ca. $24 \mathrm{~h}$ until the start of the experiment. Light was provided by eight $40 \mathrm{~W}$ cool white fluorescent tubes in the incubators. Photon flux density was set at $70 \mu \mathrm{mol}$ photons $\mathrm{m}^{-2} \cdot \mathrm{s}^{-1}$. Photoperiod was set at $12 \mathrm{~h} \mathrm{~L}$ (light):12 h D (dark).

To evaluate the combined effect of temperature and nutrient availability on growth rate and phlorotannin concentration, shoots were cultured at $10^{\circ} \mathrm{C}, 20^{\circ} \mathrm{C}, 30^{\circ} \mathrm{C}$ in both nutrient-enriched (25\% PESI) and non-enriched medium made from filtered seawater from Unosaki (i.e., a total of six treatments). Each treatment was replicated by eight times using shoots excised from eight different individuals because physiological response might differ among individuals [29]. These shoots were maintained at a photon flux density of $180 \mu \mathrm{mol}$ photons $\mathrm{m}^{-2} \cdot \mathrm{s}^{-1}$ (saturation light level for photosynthesis of this species [30]) and a photoperiod of the $12 \mathrm{~h} \mathrm{~L}: 12 \mathrm{~h}$ D for $9 \mathrm{~d}$. The culture medium in each flask was changed every 3 days. The concentrations of ammonia, nitrate, nitrite, and phosphate in both nutrient-enriched and non-enriched medium were measured at the start of the experiment using an autoanalyzer (QuAAtro 2-HR; BLTEC, Japan) with replication of 5 times.

\subsection{Measurement of Relative Growth Rate}

Wet weights of the shoots prior to the experiment (initial) and at the end (final) were measured using an electrical balance ( $0.1 \mathrm{mg}$ accuracy) after removal of excess moisture by blotting on paper towels. The initial wet weight of shoots was $1.416 \pm 0.498 \mathrm{~g}$. These shoots were cut into halves (upper and lower parts), and $0.2 \mathrm{~g}$ (wet weight) aliquots of the tissues were excised from each part for measurement of phlorotannin concentration. The remaining tissues from each part were weighed before and after drying for $72 \mathrm{~h}$ at $80^{\circ} \mathrm{C}$ in a convection oven. The ratios of dry weight to wet weight for each part of the shoots were used to convert the final wet weight into dry weight. To convert the initial wet weight into dry weight, the ratios of dry weight to wet weight of another eight shoots measured at the start of the experiment were used. The RGRs $\left(\% \mathrm{~d}^{-1}\right)$ were calculated as $100 \times \ln$ (final dry weight/initial dry weight)/9 d.

\subsection{Measurement of Phlorotannin Concentration}

Each $0.2 \mathrm{~g}$ aliquot of tissue from each part of the shoot was immediately placed in a $15 \mathrm{~mL}$ conical tube with 4 $\mathrm{mL}$ of $80 \%$ aqueous methanol at $4^{\circ} \mathrm{C}$ in the dark for $10 \mathrm{~d}$. The phlorotannin concentrations of each sample was measured using the Folin-Ciocalteu method, which provides a more consistent result and is less prone to interference by non-phenolic compounds than other colorimetric methods such as the Folin-Denis and Price-Butler methods [31], according to Kamiya et al. [32]. After incubation for $10 \mathrm{~d}$, the tissues were ground with $6 \mathrm{~mL}$ of $80 \%$ aqueous methanol using a mortar and pestle. This solution was centrifuged at $3500 \mathrm{rpm}$ at $4^{\circ} \mathrm{C}$ for $15 \mathrm{~min}$, and then the volume of the supernatant was measured ( $0.05 \mathrm{~mL}$ accuracy). One milliliter of the extract was placed in a microtube and centrifuged at $14,000 \mathrm{rpm}$ at $4^{\circ} \mathrm{C}$ for $5 \mathrm{~min}$. Next, $50 \mu \mathrm{L}$ from each extract or $80 \%$ aqueous methanol (as a reference) were added to $1 \mathrm{~mL}$ of distilled water and $1 \mathrm{~mL}$ of $40 \%$ Folin-Ciocalteu reagent (F9252, Sigma-Aldrich, St Louis, MO, USA) in an $8 \mathrm{~mL}$ glass tube. After 5 min incubation at room temperature, $1 \mathrm{~mL}$ of $2 \mathrm{~N} \mathrm{Na}_{2} \mathrm{CO}_{3}$ was added, followed by incubation in a $50^{\circ} \mathrm{C}$ water bath for $30 \mathrm{~min}$. The absorbance of each solution was then measured at $765 \mathrm{~nm}$ using a spectrophotometer (UV-1800, Shimadzu, Kyoto, Japan). Anhydrous phloroglucinol (1,3,5-trihydroxybenzene, 322-56502, Wako, Osaka, Japan) was used as the standard. The final phlorotannin concentraions were expressed as a percentage of the dry mass.

\subsection{Statistical Analysis}

Significance of effects of temperature and nutrient availability on RGR of $S$. patens shoots was analyzed by twoway ANOVA and Tukey's multiple comparison test after logarithmic transformation because some data were not normally distributed (Shapiro-Wilk test, $\mathrm{P}<0.05$ ) and did not show homogeneous variances (Levene test, $\mathrm{P}<$ 0.05). Significance of effects of temperature, nutrient availability, and parts of shoot (upper or lower part) on phlorotannin concentration of $S$. patens was analyzed by three-way ANOVA and Tukey's multiple comparison test without data transformation because some data were normally distributed (Shapiro-Wilk test, $\mathrm{P}>0.05$ ) and show homogeneous variances (Levene test, $\mathrm{P}>0.05$ ). Correlations between RGR and phlorotannin concentration were analyzed using the Pearson's test. These analyses were performed using SPSS Statistics 20.0 (IBM, Armonk, NY, USA).

\section{Results}

The concentrations of ammonia, nitrate, nitrite, and phosphate in the nutrient-enriched medium were $0.122 \pm$ $0.008,2.007 \pm 0.083,<0.005$, and $0.034 \pm 0.002 \mathrm{mg} / \mathrm{l}$, respectively, whereas those in the non-enriched medium 
were $0.026 \pm 0.003,0.009 \pm 0.002,<0.005$, and $<0.005$ $\mathrm{mg} / \mathrm{l}$, respectively.

Figure 2 shows the RGRs of $S$. patens shoots cultured in the six treatments. Results of two-way ANOVA revealed a significant effect of temperature on RGR but no significant effect of nutrient enrichment and no significant interaction between temperature and nutrient enrichment on RGR (Table 1). Results of Tukey's multiple comparison test showed that RGRs of the shoots cultured at $10^{\circ} \mathrm{C}$ were significantly lower than those of the shoots cultured at $20^{\circ} \mathrm{C}$ and $30^{\circ} \mathrm{C}$ in both enriched and non-enriched treatments.

Figure 3 shows the phlorotannin concentrations of the upper and lower parts of shoots cultured in the six treatments. Results of three-way ANOVA showed that there was a significant effect of nutrient enrichment and a significant interaction between temperature and part of the shoots on the phlorotannin concentration. However, significant effects of temperature and part of the shoot on the phlorotannin concentration were not observed (Table 1). Results of Tukey's multiple comparison test showed that the phlorotannin concentration of the upper part of the shoots cultured at $10^{\circ} \mathrm{C}$ in non-enriched medium was significant higher than those of the lower part of the shoots cultured under the same condition and of the upper part of the shoots cultured at $10^{\circ} \mathrm{C}$ in enriched medium.

Figure 4 illustrates the relationships between RGR and phlorotannin concentration of the upper and lower parts of the shoots cultured in enriched and non-enriched medium. As there was no significant effect of temperature on phlorotannnin concentration, shoots cultured at all three temperatures were regarded as one group in this analysis. Significant correlations between RGR and phlorotannin concentration were observed in the upper part of the shoot in both the enriched and non-enriched treatments, but there was no significant correlation in the low part of the shoot in either medium. Whereas a posi-

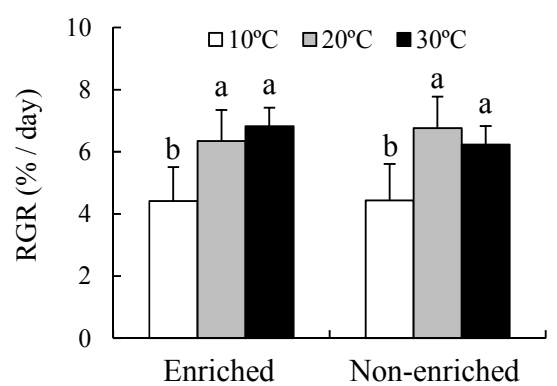

Figure 2. The RGRs (relative growth rates) of $S$. patens shoots cultured in nutrient-enriched and non-enriched medium. White, grey, and black bar indicate the RGRs at $10^{\circ} \mathrm{C}$, $20^{\circ} \mathrm{C}$, and $30^{\circ} \mathrm{C}$, respectively. Different small letters indicate statistical significances $(p<0.05)$ among different temperatures. Mean $\pm \mathrm{SD} ; \mathbf{n}=\mathbf{8}$ shoots.

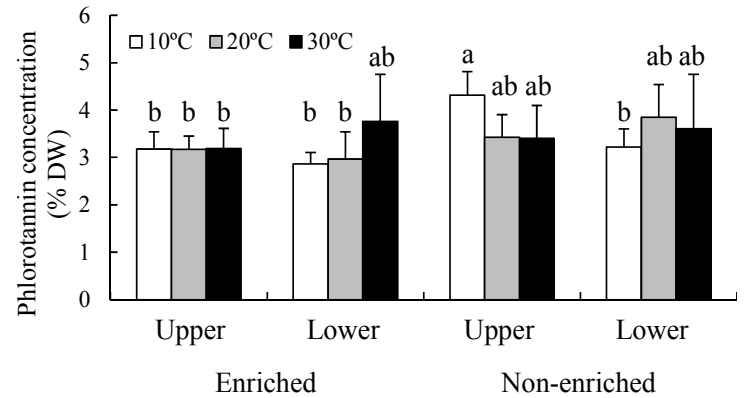

Figure 3. The phlorotannin concentrations of the upper and lower parts of $S$. patens shoots cultured in both nutrientenriched and non-enriched medium. White, grey, and black bar indicate the phlorotannin concentrations at $10^{\circ} \mathrm{C}, 20^{\circ} \mathrm{C}$, and $30^{\circ} \mathrm{C}$, respectively. Different small letters indicate statistical significances $(p<0.05)$ among different treatments. Mean \pm SD; $\mathbf{n}=\mathbf{8}$ shoots.

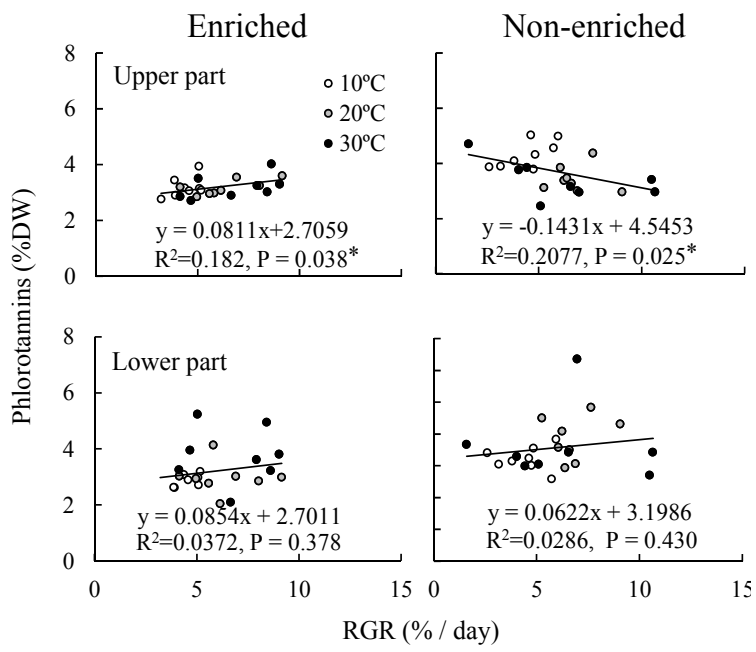

Figure 4. The relationships between RGR and phlorotannin concentration of the upper and lower parts of $S$. patens shoots cultured in nutrient-enriched and non-enriched medium. White, grey, and black points indicate the phlorotannin concentrations at $10^{\circ} \mathrm{C}, 20^{\circ} \mathrm{C}$, and $30^{\circ} \mathrm{C}$, respectively.

tive correlation was observed in the upper part of the shoot cultured in the enriched medium, a negative correlation was observed in the same part of the shoot cultured in the non-enriched medium.

\section{Discussion}

Poore et al. [4] reported that an increase in temperature from $23^{\circ} \mathrm{C}$ to $26^{\circ} \mathrm{C}$ had no effect on the phlorotannin concentration of $S$. linearifolium in their $14 \mathrm{~d}$ study. Similarly, we found no significant effect of temperature within the range of $10^{\circ} \mathrm{C}-30^{\circ} \mathrm{C}$ on phlorotannin concentration of S. patens in our present $9 \mathrm{~d}$ study. These results indicate that direct effects of temperature on phlorotannin concentration of Sargassum spp. are relatively small or cannot be detected in short-term experiments. However, 
Table 1. Results of ANOVA on the effect of temperature, nutrient, and part of shoot on RGR and phlorotannin concentration of $S$. patens shoots.

\begin{tabular}{|c|c|c|c|c|c|}
\hline Source & $\mathrm{df}$ & MS & $\mathrm{F}$ & $\mathrm{P}$ & \\
\hline \multicolumn{6}{|l|}{ RGR } \\
\hline Temperature & 2 & 0.133 & 6.315 & 0.004 & * \\
\hline Nutrient (Enriched vs. Non-enriched) & 1 & 0.004 & 0.187 & 0.668 & \\
\hline Temperature $\times$ Nutrient & 2 & 0.014 & 0.665 & 0.520 & \\
\hline \multicolumn{6}{|l|}{ Phrolotannin concentration } \\
\hline Temperature $\left(10^{\circ} \mathrm{C}, 20^{\circ} \mathrm{C}, 30^{\circ} \mathrm{C}\right)$ & 2 & 0.158 & 0.403 & 0.670 & \\
\hline Nutrient (Enriched vs. Non-enriched) & 1 & 4.761 & 12.149 & 0.001 & * \\
\hline Part of shoot (Upper vs. Lower) & 1 & 0.113 & 0.287 & 0.594 & \\
\hline Temperature $\times$ Nutrient & 2 & 1.095 & 2.793 & 0.067 & \\
\hline Temperature $\times$ Part of shoot & 2 & 2.513 & 6.412 & 0.003 & * \\
\hline Nutrient $\times$ Part of shoot & 1 & 0.170 & 0.434 & 0.512 & \\
\hline Temperature $\times$ Nutrient $\times$ Part of shoot & 2 & 1.033 & 2.636 & 0.078 & \\
\hline
\end{tabular}

we found that the RGR of S. patens shoots was significantly affected by temperature and that the phlorotannin concentration of the upper part of the shoots decreased with increasing RGR in non-enriched medium. These results suggest that temperature indirectly affects phlorotannin concentration of $S$. patens by changing the growth rate, but only in the upper part of the shoots and in the ambient nutrient condition.

The inverse relationship between growth rate and phlorotannin concentration has been reported previously [13-16]. Arnold and Targett [16] proposed that the reactive, extractable, and therefore measurable phlorotannins sequestered in the physodes (membrane-bound vesicles in the cytoplasm, which contains the high concentration of phlorotannins in the cell) serve as secondary compounds and subsequently transition to a primary role in constructing and strengthening the cell wall. This model explains that measurable phlorotannin levels can drop when the requirement for cell wall construction (i.e. growth) is high and can increase in slow-growing tissue in which rates of phlorotannin synthesis outpace rates of decomposition and incorporation of phlorotannins into cell walls $[12,16]$. In the present study, a significant correlation between RGR and phlorotannin concentration was observed in the upper part of $S$. patens shoots but not in the lower part of shoots, and was negative in the nonenriched medium but slightly positive in the enriched medium. These results can be explained by the above model, as Sargassum has meristems (fast-growing tissue) in the upper part of the shoots, and nutrient enrichment usually enhances growth of Sargassum spp. [23-25]. Although a significant effect of nutrient availability on growth rates was not detected in the present study, lower values of RGR $(1.6 \%-3.2 \%)$ were frequently observed in the non-enriched medium but not in the enriched medium. In addition, phlorotannin concentration of the upper part of the shoots cultured at $10^{\circ} \mathrm{C}$ in non-enriched medium was significantly higher than that in shoots cultured at the same temperature in the enriched medium. Therefore, the negative correlation between RGR and phlorotannin concentration of the upper part of $S$. patens shoots in non-enriched medium seems to be a result of the increased concentration of phlorotannins under slow growth rate at $10^{\circ} \mathrm{C}$ rather than decreased concentration under fast growth rate at $30^{\circ} \mathrm{C}$.

Results of the present study showed that increasing temperature indirectly affects the phlorotannin concentration of $S$. patens shoots by increasing the growth rate. As the phlorotannin concentration of the upper part of the shoots slightly decreased with increasing growth rate in the non-enriched medium, S. patens shoots seem to become palatable to herbivorous fishes, which mainly graze upper part of shoots, under warm temperature and nutrient-poor conditions during summer in the fields. In fact, Sargassum spp. are currently experiencing intensive herbivory by endemic fish species such as the rabitfish Siganus fuscescens in southern Japan [19], where the seawater temperature has increased during the last few decades [18]. However, the temperature effect on secondary chemistry of brown algae, including Sargassum spp., is poorly understood, which makes it difficult to explain the phenomena occurring in the algae fields. Although many studies have classified phlorotannin concentrations at the end of experiments as "phlorotannin levels", the turnover 
rate of phlorotannins [33] should be considered to better understand the effect of abiotic factors on phlorotannin levels. Temperature might also affect the traits of other secondary chemicals [4]. Further studies are needed to test the effects of temperature on marine plant secondary chemistry and to determine how these effects may impact plant-herbivore interactions.

\section{Acknowledgements}

We thank Prof. M. Kamiya of Fukui Prefectural University for teaching the determination methods of phlorotannin concentration. We also thank Mr. A. Nakamura, Mr. Y. Shirohata, and Mr. J. Yamada of Akita Prefectural Fisheries Promotion Center for their help with sample collection. This work was supported by JSPS KAKENHI Grant Number 24780177.

\section{REFERENCES}

[1] E. L. Zvereva and M. V. Kozlov, "Consequences of Simultaneous Elevation of Carbon Dioxide and Temperature for Plant-Herbivore Interactions: A Metaanalysis," Global Change Biology, Vol. 12, No. 1, 2006, pp. 27-41. http://dx.doi.org/10.1111/j.1365-2486.2005.01086.x

[2] M. G. Bidart-Bouzat and A. Imeh-Nathaniel, "Global Change Effects on Plant Chemical Defenses against Insect Herbivores," Journal of Integrative Plant Biology, Vol. 50, No. 11, 2008, pp. 1339-1354. http://dx.doi.org/10.1111/j.1744-7909.2008.00751.x

[3] M. I. O'Connor, "Warming Strengthens an HerbivorePlant Interaction," Ecology, Vol. 90, No. 2, 2009, pp. 388-398. http://dx.doi.org/10.1890/08-0034.1

[4] A. G. Poore, A. Graba-Landry, M. Favret, H. S. Brennand, M. Byrne and S. A. Dworjanyn, "Direct and Indirect Effects of Ocean Acidification and Warming on a Marine Plant-Herbivore Interaction," Oecologia, in press.

[5] D. B. Sudatti, M. T. Fujii, S. V. Rodrigues, A. Turra and R. C. Pereira, "Effects of Abiotic Factors on Growth and Chemical Defenses in Cultivated Clones of Laurencia dendroidea J. Agardh (Ceramiales, Rhodophyta)," Marine Biology, Vol. 158, No. 7, 2011, pp. 1439-1446. http://dx.doi.org/10.1007/s00227-011-1660-4

[6] D. R. Schiel and M. S. Foster, "The Structure of Subtidal Algal Stands in Temperate Waters," Oceanography and Marine Biology Annual Review, Vol. 24, 1986, pp. 265307.

[7] R. S. Steneck, M. H. Graham, B. J. Bourque, D. Corbett, J. M. Erlandson, J. A. Estes and M. J. Tegner, "Kelp Forest Ecosystems: Biodiversity, Stability, Resilience and Future," Environmental Conservation, Vol. 29, No. 4, 2002, pp. 436-459.

http://dx.doi.org/10.1017/S0376892902000322

[8] M. H. Graham, "Effects of Local Deforestation on the Diversity and Structure of Southern California Giant Kelp Forest Food Webs," Ecosystems, Vol. 7, No. 5, 2004, pp. 341-357.
[9] H. Christie, K. M. Norderhaug and S. Fredriksen, "Macrophytes as Habitat for Fauna," Marine Ecology Progress Series, Vol. 396, 2009, pp. 221-233. http://dx.doi.org/10.3354/meps08351

[10] X. Gao, H. Endo, K. Taniguchi and Y. Agatsuma, "Combined Effects of Seawater Temperature and Nutrient Condition on Growth and Survival of Juvenile Sporophytes of the Kelp Undaria pinnatifida (Laminariales; Phaeophyta) Cultivated in Northern Honshu, Japan," Journal of Applied Phycology, Vol. 25, No. 1, 2013, pp. 269-275. http://dx.doi.org/10.1007/s10811-012-9861-x

[11] A. G. Poore, A. H. Campbell, R. A. Coleman, G. J. Edgar, V. Jormalainen, P. L. Reynolds, E. E. Sotka, J. J. Stachowicz, R. B. Taylor, M. A. Vanderklift and J. E. Duffy, "Global Patterns in the Impact of Marine Herbivores on Benthic Primary Producers," Ecology Letters, Vol. 15, No. 8, 2012, pp. 912-922. http://dx.doi.org/10.1111/j.1461-0248.2012.01804.x

[12] C. D. Amsler and V. A. Fairhead, "Defensive and Sensory Chemical Ecology of Brown Algae," Advances in Botanical Research, Vol. 43, 2005, pp. 1-91. http://dx.doi.org/10.1016/S0065-2296(05)43001-3

[13] J. L. Yates and P. Peckol, "Effects of Nutrient Availability and Herbivory on Polyphenolics in the Seaweed Fucus versiculosus," Ecology, Vol. 74, No. 6, 1993, pp. 1757 1766. http://dx.doi.org/10.2307/1939934

[14] P. D. Steinberg, "Seasonal Variation in the Relationship between Growth Rate and Phlorotannin Production in the Kelp Ecklonia radiata," Oecologia, Vol. 102, No. 2, 1995, pp. 169-173. http://dx.doi.org/10.1007/BF00333248

[15] H. Pavia, G. Toth and P. Åberg, "Trade-Offs between Phlorotannin Production and Annual Growth in Natural Populations of the Brown Seaweed Ascophyllum nodosum," Journal of Ecology, Vol. 87, No. 5, 1999, pp. 761771. http://dx.doi.org/10.1046/j.1365-2745.1999.00397.x

[16] T. M. Arnold and N. M. Targett, "To Grow and Defend: Lack of Tradeoffs for Brown Algal Phlorotannins," Oikos, Vol. 100, No. 2, 2003, pp. 406-408. http://dx.doi.org/10.1034/j.1600-0706.2003.11680.x

[17] K. B. Hay, A. G. Poore and C. E. Lovelock, "The Effects of Nutrient Availability on Tolerance to Herbivory in a Brown Seaweed," Journal of Ecology, Vol. 99, No. 6, 2011, pp. 1540-1550. http://dx.doi.org/10.1111/j.1365-2745.2011.01874.x

[18] K. Tanaka, S. Taino, H. Haraguchi, G. Prendergast and M. Hiraoka, "Warming off Southwestern Japan Linked to Distributional Shifts of Subtidal Canopy-Forming Seaweeds," Ecology and Evolution, Vol. 2, No. 11, 2012, pp. 28542865. http://dx.doi.org/10.1002/ece3.391

[19] A. Yamaguchi, K. Furumitsu, N. Yagishita and G. Kume, "Biology of Herbivorous Fish in the Coastal Areas of Western Japan," In: A. Ishimatsu and H. J. Lie, Eds., Coastal Environmental and Ecosystem Issues of the East China Sea, Nagasaki University, TERRAPUB, Tokyo, 2010, pp. 181-190.

[20] T. Yoshida, "Marine Algae of Japan," Uchida Roukakuho Publishing, Tokyo, 1998.

[21] P. O. Ang Jr., "Phenology of Sargassum spp. in Tung 
Ping Chau Marine Park, Hong Kong SAR, China," Journal of Applied Phycology, Vol. 18, No. 3-5, 2006, pp. 629-636. http://dx.doi.org/10.1007/s10811-006-9071-5

[22] K. Taniguchi and Y Yamada, "Ecological Study on Sargassum patens C. Agardh, and S. serratifolium C. Agardh in the Sublittoral Zone at Iida Bay on Noto Peninsula in the Japan Sea," Bulletin of Japan Sea Regional Fisheries Research Laboratory, Vol. 29, 1978, pp. 239-253.

[23] B. Schaffelke and D. W. Klumpp, "Nutrient-Limited Growth of the Coral Reef Macroalga Sargassum baccularia and Experimental Growth Enhancement by Nutrient Addition in Continuous Flow Culture," Marine Ecology Progress Series, Vol. 164, 1998, pp. 199-211. http://dx.doi.org/10.3354/meps 164199

[24] B. Schaffelke and D. W. Klumpp, "Short-Term Nutrient Pulses Enhance Growth and Photosynthesis of the Coral Reef Macroalga Sargassum baccularia," Marine Ecology Progress Series, Vol. 170, 1998, pp. 95-105. http://dx.doi.org/10.3354/meps170095

[25] R.-L. Hwang, C.-C. Tsai and T.-M. Lee, "Assessment of Temperature and Nutrient Limitation on Seasonal Dynamics among Species of Sargassum from a Coral Reef in Southern Taiwan," Journal of Phycology, Vol. 40, No. 3, 2004, pp. 463-473. http://dx.doi.org/10.1111/j.1529-8817.2004.03086.x

[26] K. Gao, "Comparative Photosynthetic Capacities of different Parts of Sargassum horneri (Phaeophyta)," Japanese Journal of Phycology (Sôrui), Vol. 39, 1991, pp. 245-252.

[27] H. Haraguchi, N. Murase, Y. Mizukami, M. Noda, G. Yoshida and T. Terawaki, "The Optimal and Maximum
Critical Temperatures of Nine Species of the Sargassaceae in the Coastal Waters of Yamaguchi Prefecture," Japanese Journal of Phycology, Vol. 53, No. 1, 2005, pp. 7-13.

[28] M. Tatewaki, "Formation of a Crustaceoussporophyte with Unilocularsporangia in Scytosiphon lomentaria," Phycologia, Vol. 6, No. 1, 1966, pp. 62-66. http://dx.doi.org/10.2216/i0031-8884-6-1-62.1

[29] V. Jormalainen and T. Ramsay, "Resistance of the Brown Alga Fucus vesiculosus to Herbivory," Oikos, Vol. 118, No. 5, 2009, pp. 713-722. http://dx.doi.org/10.1111/j.1600-0706.2008.17178.x

[30] K. Gao and I. Umezaki, "Comparative Photo Synthetic Capacities of the Leaves of Upper and Lower Parts of Sargassum Plants," Botanica Marina, Vol. 31, No. 3, 1988, pp. 231-236.

http://dx.doi.org/10.1515/botm.1988.31.3.231

[31] K. L. van Alstyne, "Comparison of Three Methods for Quantifying Brown Algal Polyphenolic Compounds," Journal of Chemical Ecology, Vol. 21, No. 1, 1995, pp. 45-58. http://dx.doi.org/10.1007/BF02033661

[32] M. Kamiya, T. Nishio, A. Yokoyama, K. Yatsuya, T. Nishigaki, S. Yoshikawa and K. Ohki, "Seasonal Variation of Phlorotannin in Sargassacean Species from the Coast of the Sea of Japan," Phycological Research, Vol. 58, No. 1, 2010, pp. 53-61. http://dx.doi.org/10.1111/j.1440-1835.2009.00558.x

[33] T. M. Arnold and N. M. Targett, "Evidence for Metabolic Turnover of Polyphenolics in Tropical Brown Algae," Journal of Chemical Ecology, Vol. 26, No. 6, 2000, pp. 1393-1410. http://dx.doi.org/10.1023/A:1005588023887 